\title{
Avaliação da Periculosidade Ambiental de Bioinseticidas como uma Nova Perspectiva para a Ecotoxicologia no Brasil
}

\author{
E. C. Oliveira-Filho \\ Embrapa Cerrados, Rodovia BR 020, km 18, CEP 73310-970, Planaltina, DF, Brasil
}

(Received July 7, 2007; Accepted April 15, 2008)

\begin{abstract}
RESUMO
Os produtos biológicos ou biopesticidas têm se apresentado, tanto na agropecuária quanto no controle de mosquitos, como interessante alternativa ao uso dos tradicionais produtos químicos. $\mathrm{O}$ fato de terem efeito inseticida, independentemente da sua origem, enquadra os produtos biológicos na legislação federal de agrotóxicos. As principais preocupações existentes estão relacionadas aos possíveis impactos sobre o meio ambiente e sobre a saúde da população exposta. Recentemente, com a publicação da Instrução Normativa Conjunta n⿳o 3, de 10 de março de 2006, os órgãos reguladores definiram requisitos específicos para o registro de bioinseticidas no Brasil, entre os quais a realização de ensaios de ecotoxicidade. Nesse contexto, a presente revisão informa quais são os microrganismos registrados para uso no Brasil, discorre sobre os ensaios solicitados para registro de produtos e apresenta resultados disponíveis na literatura sobre a ecotoxicidade de agentes utilizados para essa finalidade. Os estudos levantados mostram diferentes situações nas quais muitas vezes o agente não apresenta especifi-cidade na sua ação tóxica, e organismos não-alvo também podem ser atingidos. Além disso, a obtenção desses dados poderá nortear as pesquisas com microrganismos, predizendo a viabilidade ambiental de seu lançamento em grande escala nos experi-mentos de campo. Todas essas informações enfatizam a importância da ecotoxicologia na avaliação da periculosidade ambien-tal dos bioinseticidas e configuram tal campo de atuação como promissor para essa ciência.
\end{abstract}

Palavras-chave: biopesticidas, regulação, ecotoxicidade, controle biológico, toxicologia.

\section{ABSTRACT}

\section{Environmental hazard assessment of bioinsecticides as a new perspective for ecotoxicology in Brazil}

Biological products or biopesticides have been presented as an interesting alternative to the traditional chemical products used to control pests in livestock, agriculture and public health. Due to its insecticide action, independent of their origin, these products are regulated by the federal legislation of pesticides. The main concerns are related to the potential impacts on the environment and on the health of the exposed population. Recently, with the publication of the Normative Instruction $\mathrm{n}^{\mathrm{O}} 3$, in March 10 of 2006, regulatory agencies have defined specific requirements for biopesticides registration in Brazil, and among these requirements are several ecotoxicity assays. In this way, this review inform what are the microorganisms with registration for use in Brazil, describes the assays requested for registration and comments available results in literature about the ecotoxicity of these agents. The studies presented showed different situations where many times the agent's specificity is not so significant and in some cases non-target species can be affected. Besides, the acquisition of these data could orientate the researches with microorganisms predicting the environmental feasibility of its releases in field experiments. All these information emphasize the importance of ecotoxicology in the environmental hazard assessment of bioinsecticides and configure this field of action as more one for this science in Brazil.

Key words: biopesticides, regulation, ecotoxicity, biological control, toxicology.

*Corresponding author: Eduardo Cyrino Oliveira-Filho, e-mail: cyrino@cpac.embrapa.br. 


\section{INTRODUÇÃO}

Os insetos são responsáveis por perdas agrícolas e transmissão de várias doenças. A principal forma de controle tem sido a utilização de produtos químicos. Os problemas derivados do contínuo e descontrolado uso de tais produtos têm sido intensamente relatados, ocasionando desde a contaminação do meio ambiente até a intoxicação de seres humanos. Desse modo, o uso de inseticidas biológicos torna-se uma alternativa altamente viável e interessante, visto que os microrganismos selecionados são encontrados no ambiente natural.

No Brasil, os produtos biológicos utilizados para o controle de pragas agrícolas são regulados pela Lei $\mathrm{n}^{\mathrm{O}} 7.802$, de 11 de julho de 1989 (Brasil, 1989), a Lei de Agrotóxicos e Afins. Para tanto, essa Lei define agrotóxicos e afins como "os produtos e os agentes de processos físicos, químicos ou biológicos, destinados ao uso nos setores de produção, no armazenamento e beneficiamento de produtos agrícolas, nas pastagens, na proteção de florestas, nativas ou implantadas, e de outros ecossistemas e também de ambientes urbanos, hídricos e in-dustriais, cuja finalidade seja alterar a composição da flora ou da fauna, a fim de preservá-las da ação danosa de seres vivos considerados nocivos". Nesse contexto, enquadram-se tanto os agentes de controle biológico (entomopatógenos, para-sitóides, predadores e nematóides) como os agentes de controle comportamental (feromônios) utilizados na agricultura com a finalidade de controlar outras espécies consideradas nocivas. Por serem enquadrados na Lei $\mathrm{n}^{\mathrm{o}} 7.802 / 89$, os produtos bio-lógicos devem seguir o Decreto $\mathrm{n}^{\mathrm{o}} 4.074$, de 8 de janeiro de 2002 (Brasil, 2002), que regulamenta a Lei, além dos instrumentos jurídicos normativos específicos existentes para cada um desses agentes. Pela definição da legislação, deve-se destacar que não é a origem dos produtos que os classificam nesse contexto, mas sim a finalidade para a qual eles se destinam, ou seja, controlar seres vivos considerados nocivos. O Decreto $\mathrm{n}^{\mathrm{o}}$ 4.074/02 estabelece o registro como uma condição para produção, manipulação, importação, exportação, comercialização e utilização dos agrotóxicos, seus componentes e afins em todo o território nacional, ou seja, o registro é a maneira legal de um produto agrotóxico ser comercializado no Brasil, seja por intermédio de formulação/fabricação dos seus componentes e/ou de importação dos mesmos. O objetivo do registro, entre outras coisas, é garantir a segurança da população e do meio ambiente, além de garantir padrões de qualidade e eficiência para os produtos a serem comercializados (Oliveira-Filho \& Castro, 2006).

No Brasil, o Ministério da Agricultura Pecuária e do Abastecimento (MAPA), a Agência Nacional de Vigilância Sanitária (ANVISA) e o Instituto Brasileiro do Meio Ambiente e dos Recursos Naturais Renováveis (IBAMA) são os órgãos federais responsáveis pela avaliação e pelo registro de agrotóxicos e afins. Segundo o Decreto $\mathrm{n}^{\mathrm{o}}$ 4.074/02, aqueles que solicitam o registro devem submeter, a cada um dos órgãos citados, informações e dados específicos para que os produtos sejam propriamente avaliados. Excepcionalmente, os produtos a serem utilizados no ambiente domiciliar (domissanitários) e em campanhas de saúde pública são regidos pela Lei $\mathrm{n}^{\mathbf{o}}$ 6.360, de 23 de setembro de 1976 (Brasil, 1976), e por esse motivo são avaliados e têm seu registro concedido única e exclusivamente pela Gerência Geral de Saneantes da ANVISA, o que é um problema do ponto de vista da segurança ambiental (Maximiano et al., 2004).

De modo geral, as principais dúvidas dos órgãos reguladores estão relacionadas à similaridade entre o modo de ação dos produtos biológicos e dos produtos químicos convencionais, ou seja, os possíveis impactos da utilização desses produtos sobre o meio ambiente e sobre a saúde da população exposta. As exigências fazem sentido, já que, mesmo sendo um produto natural, o principal questionamento seria sobre quais conseqüências poderiam ser geradas a partir da utilização desses produtos em concentrações acima daquelas encontradas natu-ralmente. A partir desse ponto surge a relevância de informações, como: a toxicidade de potenciais toxinas, dados de irritabilidade, alergenicidade e patogenicidade para espécies não-alvo. Assim sendo, justificam-se a avaliação prévia e os testes de segurança requeridos, de forma a obter dados de identificação do perigo oferecido pelo agente, no contexto de um processo de avaliação de risco (Oliveira-Filho \& Castro, 2006).

A demanda global pela utilização de produtos eficazes e menos poluentes (naturais) tem aumentado, e nesse ponto o incremento da comercialização de produtos à base de microrganismos entomopatogênicos (microbiológicos) deve-se principalmente ao incremento das pesquisas nesse setor. Todavia, até bem pouco tempo, todo o processo de avaliação e registro de produtos era voltado exclusivamente para a avaliação de substâncias químicas (agrotóxicos convencionais), e os produtos biológicos, totalmente distintos, vinham sendo enquadrados nesses protocolos (Oliveira-Filho, 2005).

No Brasil, a partir de 1997, a legislação começa a se adequar aos padrões internacionais. Nesse ano, com o apoio da comunidade científica o IBAMA publicou a Portaria Normativa $\mathrm{n}^{\mathrm{o}} 131$, de 3 de novembro de 1997 (IBAMA, 1997), preconizando a avaliação toxicológica e ecotoxicológica de produtos bioló-gicos em três fases, conforme memorando indicativo da Orga-nização Mundial da Saúde (WHO, 1981). Nesse contexto, é solicitada ainda, a avaliação da patogenicidade de produtos à base de microrganismos, o que até então era um tipo de avaliação ainda inexistente no cenário legislativo nacional.

Em 2002, a ANVISA, contando também com o apoio de pesquisadores, representantes do IBAMA e do MAPA, publicou, em 8 de julho de 2002, a RDC n⿳丷ㅜ 194 (ANVISA, 2002), uma resolução com modelo muito parecido com a Portaria $\mathrm{n}^{\mathrm{o}}$ 131/ 97 do IBAMA, preconizando a avaliação toxicológica e da patogenicidade de agentes microbiológicos de controle. De modo geral, ambas são semelhantes ao modelo da Agência de Proteção Ambiental dos Estados Unidos (USEPA), que sugere a avaliação em três fases contemplando uma mistura de testes toxicológicos convencionais e de testes para avaliar a patogenicidade do microrganismo candidato. Recentemente, com a publicação da Instrução Normativa (IN) Conjunta $\mathrm{n}^{\mathrm{o}}$ 03, de 10 de março de 2006 (Brasil, 2006), entre MAPA, ANVISA e 
IBAMA, foram definidos critérios e exigências específicas para o registro de agentes microbiológicos de controle (AMCs), no Brasil.

Nesse contexto, em função da importância das normas publicadas e do aumento na pesquisa com agentes microbiológicos de controle (AMCs), essa revisão tem por objetivo discorrer sobre os principais ensaios ecotoxicológicos solicitados para registro de um $\mathrm{AMC}$, enfocando no pequeno número de dados disponíveis na literatura e ressaltando a importância dessa nova área de atuação e pesquisa para os profissionais de ecotoxicologia no Brasil.

\section{Regulação de bioinseticidas no Brasil e no Mundo}

Os bioinseticidas são também chamados de entomopatógenos, pois, em geral, são microrganismos que causam doenças nos insetos. Na maioria dos casos, o efeito se dá devido à presença de toxinas específicas que têm sua ação no interior do inseto-alvo.

No Brasil, os bioinseticidas são legalmente denominados de agentes microbiológicos de controle (AMCs) e definidos pela Instrução Normativa Conjunta $\mathrm{n}^{\mathrm{o}}$ 03, de 10 de março de 2006 (Brasil, 2006), como "os microorganismos vivos de ocorrência natural, bem como aqueles resultantes de técnicas que impli-quem a introdução natural de material hereditário", utilizados no controle de espécies consideradas nocivas.

Um dos bioinseticidas mais conhecidos em todo o mundo é a bactéria entomopatogênica Bacillus thuringiensis. O primeiro produto comercial dessa bactéria, chamado Sporeine-, estava disponível em 1938 na França (Van Frankenhuyzen, 1993). Nos Estados Unidos (EUA), o primeiro agente microbiológico para controle de pragas (Bacillus popilliae) foi registrado em 1948 pelo Departamento de Agricultura daquele país. Somente em 1957 foi produzida a primeira formulação comercial de B. thuringiensis. Atualmente, nos Estados Unidos estão regis-trados cerca de 84 ingredientes ativos biológicos, compondo em torno de 262 produtos à base de microrganismos (USEPA, 2007).

No Brasil, o registro de AMCs é bem recente. Segundo dados do Sistema de Informação sobre Agrotóxicos (SIA), os primeiros inseticidas à base de $B$. thuringiensis registrados datam de 1991. Contudo, outros microrganismos também têm registro como bioinseticidas no Brasil: Bacillus sphaericus, para controle de larvas de mosquitos transmissores de doenças; Nucleopolihedrovirus anticarsia gemmatalis (Baculovirus anticarsia), para controle da lagarta de mesmo nome; além dos fungos Beauveria bassiana e Metarhizium anisopliae, para uso agrícola, que ao lado do Bacillus thuringiensis totalizam cerca de apenas dez produtos registrados (ANVISA, 2006). Cabe ressaltar que muitas vezes microrganismos da mesma espécie possuem diversas toxinas e, por conta disso, diferentes alvos biológicos, em função, sobre-tudo, de mudanças de subespécie, raça, cepa, variedade ou isolado (Praça et al., 2004), o que gera a necessidade de avaliação toxicológica para cada produto.

As normas para avaliação ecotoxicológica desses produ-tos são similares entre os vários países que os utilizam. O Canadá segue os protocolos e os modelos da agência ambiental ameri- cana, e os países da União Européia têm normas próprias, mas que pouco diferem da anterior. $\mathrm{O}$ modelo de avaliação em três fases proposto pela OMS (WHO, 1981) é a linha orientadora, com pequenas alterações na recomendação de um ou outro teste em cada fase. Esse modelo propõe, na fase I, a realização de testes de toxicidade básicos; na fase II, testes comple-mentares, no caso de haver evidências de efeitos na fase I; e, na fase III, testes de mais alta complexidade, quando houver evidências de danos nos testes na fase II. Em geral, um micror-ganismo candidato não chega a ser avaliado na fase III, pois os altos custos dos testes inviabilizam seu uso.

\section{Estudos ecotoxicológicos}

Para fins de registro no Brasil, o IBAMA, como representante do Ministério do Meio Ambiente, executa a avaliação e classificação da periculosidade ambiental de todos os produtos regidos pela Lei $\mathrm{n}^{\mathbf{0}} 7.802 / 89$, entre os quais os bioinseticidas, por meio da observação de parâmetros físico-químicos, de comportamento ambiental e de estudos toxicológicos e ecotoxicológicos. De acordo com a IN Conjunta $n^{0} 03 / 06$, os principais estudos ecotoxicológicos solicitados são: fase I ensaios de toxicidade aguda para invertebrados de água doce, peixes de água doce, insetos não-alvo, abelhas e toxicidade oral aguda para aves; fase II - estudos de comportamento dos agentes no ambiente terrestre, no ambiente de água doce e no ambiente estuarino; fase III - ensaios de toxicidade com organismos silvestres terrestres e aquáticos, patogenicidade e reprodução em aves, especificidade para invertebrados, ciclo biológico de peixes e plantas não-alvo. Essa IN ainda prevê a fase IV, que contempla os testes simulados em ambientes naturais. Obviamente, os ensaios da fase inicial são os mais executados, tanto no âmbito da academia quanto pelos interessados no registro, principalmente por serem mais simples, do ponto de vista operacional, além de gerarem resultados mais rápidos e objetivos para a determinação da periculosidade do agente. Esses ensaios de toxicidade aguda pouco diferem daqueles tradicionalmente já empregados para avaliação de substâncias químicas, já que, nesse caso, o objetivo principal é a deter-minação dos efeitos de potenciais toxinas. Por sua vez, os estudos envolvendo mamíferos também fazem parte das exigências para avaliação toxicológica dos bioinseticidas, sendo realizados em três fases. Tais testes são igualmente solicitados pela ANVISA como subsídio para a avaliação de perigo à saúde humana. Nesse caso, já na primeira fase de avaliação, têm grande importância o estudo dos potenciais patogênico e infectivo dos microrganismos além do estudo de possível toxicidade devido à presença de toxinas.

Embora os AMCs candidatos sejam patógenos naturais das espécies-alvo, a aplicação desses organismos de maneira antrópica gera, também, preocupação com a segurança am-biental, pois a utilização desses patógenos no ambiente tem por objetivo causar danos somente à espécie-alvo. Segundo Ignoffo (1973), questionamentos desse tipo têm motivado expe-rimentos desde o desenvolvimento dos primeiros AMCs, com principal enfoque na observação de efeitos sobre insetos não-alvo, algumas aves e peixes. Nesse período, o maior temor ocorreu 
quando da proposta de uso de AMCs, em ambientes aquáticos, para controle de larvas de insetos vetores de doenças. Desde então, vários estudos para avaliar os efeitos de AMCs sobre organismos não-alvo têm sido realizados (Lacey \& Mulla, 1990).

\section{Ecotoxicidade de bioinseticidas bacterianos}

Por ser um dos primeiros microrganismos utilizados como bioinseticida, a bactéria Bacillus thuringiensis é uma das mais estudadas. Embora o sistema de fases seja atualmente a principal estratégia das avaliações de periculosidade ambiental dos bioinseticidas, várias outras investigações foram realizadas com o $B$. thuringiensis $(B t)$.

Para avaliar os possíveis impactos do $B t$ sobre inverte-brados aquáticos, vários ensaios com diferentes organismos foram realizados, entre estes Daphnia magna, Cyclops sp. e Rivulogammarus pulex, que não foram afetadas pelo bioin-seticida, contudo, o crustáceo da ordem anostraca Chirocephalus grubei apresentou mortalidade de $57 \%$ quando exposto à concentração de 18 ppm, o equivalente a cem vezes a concen-tração larvicida utilizada para controle de mosquitos (Lacey \& Mulla, 1990). Em estudos realizados com moluscos, planárias e anfíbios, também não foram observados efeitos adversos após a exposição à concentração de $180 \mathrm{ppm}$ (Boisvert \& Boisvert, 2000). Em outro estudo, realizado nos Estados Unidos, Merritt et al. (1989) relataram ausência de evidência de efeitos sobre a comunidade de invertebrados aquáticos, após a execução de um programa de controle. Com relação aos efeitos sobre inverte-brados do solo, Addison (1993) observou que nematóides e besouros podem estar em risco após a aplicação do $B t$. Se-gundo o autor todas as cepas de $B t$ testadas foram tóxicas para ovos do nematóide Trichostrongylus colubriformis.

Em estudo com várias espécies de peixe, expostas por 30 dias a concentrações entre $10^{9}$ e $10^{10}$ unidades formadoras de colônia (UFC)/mL, não houve evidências de mortalidade, patogenicidade ou infectividade (WHO, 1999). Num outro trabalho, com B. thuringiensis kurstaki, foi observada a mortalidade de $20 \%$ das trutas expostas ao final do experimento de 32 dias, sendo esta atribuída à excessiva competição por alimento na água, extremamente turva pela presença das altas concentrações do microrganismo (WHO, 1999). Mittal et al. (1994) alimentaram peixes da espécie Poecilia reticulata com larvas contaminadas por vários inseticidas químicos e biológicos. Não foi observada nenhuma mortalidade nos peixes que se alimentaram das larvas contendo Bt. Por outro lado, Snarski (1990) observou morta-lidade de larvas do peixe Pimephales promelas expostas a concentrações da ordem de $10^{6} \mathrm{UFC} / \mathrm{mL}$.

A toxicidade aguda e a patogenicidade de diferentes formulações comerciais de $B t$ foram avaliadas para várias espécies de aves, entre elas Colinus virginianus, uma espécie de codorna, e Anas platyrhynchus, uma espécie de pato, por meio da administração via oral, em doses na ordem de $10^{9}$ a $10^{11} \mathrm{UFC} / \mathrm{Kg} /$ dia. Não foram verificados efeitos adversos às espécies testadas durante todo o período de observação dos ensaios (WHO, 1999).

Innes \& Bendell (1989) avaliaram, por 90 dias, os efeitos de uma formulação comercial de B. thuringiensis kurstaki sobre populações de pequenos mamíferos silvestres. Os resultados observados sugeriram que a ingestão de insetos contaminados não gerou efeitos adversos nessas populações.

De fato, o maior problema dos inseticidas à base de $B$. thuringiensis tem sido seu efeito contra insetos não-alvo (USEPA, 1998). Segundo Polanczyk \& Alves (2003) dez ordens de insetos são suscetíveis, ou seja, podem sofrer algum dano após exposição ao Bacillus thuringiensis. Dessas, a ordem Lepidoptera é a mais atingida, com 572 espécies suscetíveis, seguida por Diptera, com 266 espécies, Coleoptera, 106, Hymenoptera, 62, Hemiptera, 48, Syphonaptera ,7, Orthoptera, 6, Isoptera, 5, Neuroptera, 4 e Thysanoptera, 3, totalizando 1079 espécies.

Segundo Lacey \& Siegel (2000), em comparação com o Bt, há poucos dados disponíveis sobre os efeitos de Bacillus sphaericus sobre invertebrados. Sendo essa espécie extrema-mente eficiente para o controle de larvas de mosquitos, a obtenção de dados sobre efeitos adversos em organismos aquáticos torna-se de grande relevância. Em um estudo realizado na Índia, Mathavan \& Velpandi (1984) testaram os efeitos de duas cepas de B. sphaericus sobre os crustáceos de água doce,

Daphnia similis e Streptocephalus dichotomus, além do anelídeo Tubifex tubifex. Para todas as espécies-teste os efeitos adversos só se manifestaram em concentrações 2.500 a 27.000 vezes maiores do que a necessária para a obtenção do efeito larvicida. Com a lagosta Procambarus clarkii, Holck \& Meek (1987) observaram valores letais apenas em concentrações mil vezes maior do que a necessária para matar as larvas de inseto. Segundo Walton \& Mulla (1991), em um experimento de meso-cosmos utilizando o peixe Gambusia affinis e a bactéria B. sphaericus para controle de larvas de mosquito, houve grande decréscimo das larvas sem a observação de efeitos adversos aos peixes. Saik et al. (1990) relatam vários estudos realizados com mamíferos sem resultados dignos de nota. Segundo os autores, inúmeras cepas de Bacillus sphaericus foram injetadas por diversas vias em camundongos, ratos, cobaias e coelhos, para avaliações agudas e crônicas, e, das poucas lesões observadas, várias também foram registradas nos animais que receberam material autoclavado, indicando, provavelmente, um dano físico.

De modo geral, na maioria das pesquisas realizadas em que foi registrado algum tipo de efeito adverso, os danos são justificados pelo contato físico ou pela alta concentração do produto, o que pode gerar aumento de turbidez na água, supressão do oxigênio dissolvido ou, muitas vezes, toxicidade dos componentes químicos presentes nas formulações dos produtos.

\section{Ecotoxicidade de bioinseticidas fúngicos}

Embora a maioria dos fungos utilizada no controle biológico tenha ação inseticida, algumas espécies também são utilizadas na agricultura contra plantas daninhas ou mesmo contra outros fungos (Tigano \& Mello, 2006). Fournie et al. (1988) avaliaram os efeitos do herbicida fúngico Colletotrichum gloeosporioides sobre organismos não-alvo, incluindo plantas aquáticas, moluscos, crustáceos e peixes, por meio da expo-sição por 28 dias a uma concentração mil vezes maior que a 
de uso em campo. Os dados obtidos mostraram pequena mortalidade entre os organismos de estuário expostos. O autor creditou esse efeito à deterioração da qualidade da água devido ao crescimento de bactérias. Em outro estudo, Jonsson \& Genthner (1997) demonstraram ausência de efeitos desse mesmo fungo sobre os crustáceos Palaemonetes pugio e Artemia salina. O inseticida fúngico aquático Lagenidium giganteum também foi testado contra várias espécies em testes de ecotoxicidade clássicos. A sobrevivência e a reprodução do microcrustáceo Ceriodaphnia dubia foram afetadas em concentrações acima de 6.250 zoosporos/mL (Nestrud \& Anderson, 1994).

Os efeitos adversos do fungo Trichoderma stromaticum foram avaliados sobre a microalga Selenastrum capricornutum, o microcrustáceo Daphnia similis, o peixe Hyphessobrycon scholzei e ratos Wistar representando os mamíferos. Os resul-tados mostraram ausência de efeitos adversos para as algas, os peixes e os ratos, contudo $30 \%$ da taxa reprodutiva de Daphnia similis foi inibida na concentração de $10^{6}$ esporos/ mL. Os autores do estudo relatam que em função desse resul-tado seriam necessários estudos complementares da fase II para avaliar a persistência do fungo no ambiente aquático (Castro et al., 2001).

As espécies de fungo Metarhizium anisopliae e Beauveria bassiana têm registro para uso no Brasil. Genthner \& Middaugh (1995) avaliaram os efeitos de M. anisopliae sobre embriões do peixe Menidia beryllina. Nesse estudo foram observados vários efeitos adversos sobre os embriões e as larvas recém-eclodidas. Genthner et al. (1998) também mostraram os efeitos desse fungo sobre embriões do crustáceo Palaemonetes pugio e da rã Xenopus laevis. Sobre a espécie Beauveria bassiana, Middaugh \& Genthner (1994) também observaram efeitos tera-togênicos desse fungo sobre embriões e larvas do peixe Menidia beryllina. Em outro estudo, Genthner et al. (1994) determinaram a $\mathrm{CL}_{50}$ de $0,56 \mathrm{mg} / \mathrm{L}$ da beauvericina, uma toxina liberada por algumas cepas de $B$. bassiana, sobre o crustáceo Mysidopsis bahia. Nesse mesmo trabalho os autores observa-ram alta mortalidade de organismos em concentrações a partir de $1,5 \cdot 10^{6}$ esporos $/ \mathrm{mL}$.

A toxicidade e a patogenidade dessa espécie de fungo para mamíferos foi testada pela via intramuscular de camun-dongos sem observação de infecção, multiplicação ou persis-xtência do microrganismo após três dias (Semalulu et al., 1992).

\section{Ecotoxicidade de bioinseticidas virais}

Uma grande quantidade de tipos de vírus oferece potencial para controle biológico de insetos. Desses, os mais bem estu-dados estão no grupo Baculoviridae, sendo os principais gêneros NPV - Nucleopoliedrovirus e GV Granulovirus. Em geral, esses vírus apresentam espectro de ação focado em cerca de 43 espécies de 11 famílias da ordem lepidóptera (Lacey et al., 2001). O principal mecanismo de transmissão viral nos lepidópteros é por meio da liberação de partículas denominadas corpos de oclusão.
Embora os vírus estejam entre os inseticidas biológicos menos estudados, este foi um dos primeiros grupos a solicitar registro nos Estados Unidos, juntamente com os Bacillus. O NPV Heliothis indubitavelmente foi o mais extensivamente estudado entre os vírus entomopatogênicos, não somente sobre vertebrados como também para invertebrados e plantas. A partir de 1963, o NPV Heliothis foi sistematicamente testado contra várias espécies não-alvo, de modo a garantir a segurança de seu uso. As doses e concentrações utilizadas foram de dez a cem vezes maiores que a média utilizada em campo, e em nenhum dos ensaios foi observada toxicidade ou patogenicidade, a não ser para as espécies-alvo (Ignoffo, 1973).

A Tabela 1 mostra resultados de ensaios de ecotoxicidade de dois nucleopoliedrovírus, apresentados à agência de proteção ambiental dos Estados Unidos para a renovação do registro desses bioinseticidas virais. Em todos os casos não foi observado efeito adverso aos organismos não-alvo testados (USEPA, 1996).

\section{CONSIDERAÇÕES FINAIS}

Com o aumento mundial de demanda por alimentos "mais limpos" e por produtos considerados de baixa toxicidade e periculosidade, torna-se de grande relevância a avaliação da segurança ambiental dos bioinseticidas. Ressalta-se a importância da modernização da legislação nacional, que vem aprimo-rando significativamente a diferenciação entre produtos biológicos e produtos químicos. Uma das grandes falhas no aspecto legislativo é que, para o registro de produtos a serem utilizados no controle de vetores (saúde pública), os requisitos são diferenciados e em geral, não há a participação do IBAMA no processo, o que gera grande deficiência no processo de avaliação da periculosidade ambiental.

A grande diversidade de cepas e espécies de microrganismos pesquisadas com finalidade bioinseticida necessita seguramente de avaliação ecotoxicológica, tendo em vista as inúmeras alterações nas toxinas presentes que podem indiscu-tivelmente modificar a toxicidade dos produtos e, muitas vezes, inviabilizar seu uso em situações de campo.

A determinação da ecotoxicidade é um componente fundamental na avaliação da periculosidade e do risco ambiental de agentes químicos e biológicos. Embora a avaliação de risco dos produtos agrotóxicos e afins já esteja prevista na legislação federal brasileira (Decreto $\mathrm{n}^{\mathrm{O}}$ 4.074/00), os órgãos reguladores ainda não definiram procedimentos para a implementação desse processo e, desse modo, os dados de ecotoxicidade têm sido utilizados basicamente para definição da viabilidade e periculosidade ambiental de um produto químico ou biológico a ser utilizado no controle de pragas.

As informações apresentadas nesta revisão mostram que, assim como ocorre com as substâncias químicas, há microrganismos ou produtos bioinseticidas mais ou menos tóxicos, e que, pelas recentes publicações normativas governamentais a produção e o uso de produtos dessa natureza tendem a aumentar significativamente nos próximos anos. 
Tabela 1 - Efeitos dos Nucleopoliedrovirus Lymantria dispar e Orgyia pseudotsugata sobre organismos não-alvo, segundo USEPA (1996).

\begin{tabular}{|c|c|c|}
\hline Estudo & Tipo de estudo & Resultado \\
\hline Invertebrados de água doce & $\begin{array}{l}\text { Exposição de Daphnia magna, } \\
\text { Notonecta undulata e } \\
\text { Chironomus thummi }\end{array}$ & $\mathrm{CL}_{50}>250$ corpos de oclusão/mL \\
\hline $\begin{array}{l}\text { Toxicidade/patogenicidade } \\
\text { c/ peixes de água doce }\end{array}$ & $\begin{array}{l}96 \mathrm{hr}-\mathrm{CL}_{50}-\text { truta marrom e } \\
\text { Lepomis macrochirus }\end{array}$ & $\begin{aligned} \mathrm{CL}_{50} & >1,5 \cdot 10^{9} \text { corpos de } \\
& \text { oclusão/grama }\end{aligned}$ \\
\hline $\begin{array}{l}\text { Toxicidade/patogenicidade } \\
\text { c/ abelhas }\end{array}$ & Alimentação por quatro meses & $\begin{array}{c}\text { Ausência de efeitos sobre a postura, } \\
\text { crescimento dos filhotes e produção de } \\
\text { mel }\end{array}$ \\
\hline \multirow{2}{*}{$\begin{array}{l}\text { Toxicidade/patogenicidade } \\
\text { oral aguda em aves }\end{array}$} & Alimentação de codornas & $\begin{array}{l}\text { Sem sinais de toxicidade ou } \\
\text { patogenicidade na dose de } 3,73 \cdot 10^{3} \\
\text { corpos de oclusão/grama/indivíduo }\end{array}$ \\
\hline & Alimentação de passarinhos & $\begin{array}{l}\text { Os pássaros se alimentaram de larvas } \\
\text { infectadas com } 3 \cdot 10^{7} \text { a } 2 \cdot 10^{8} \\
\text { corpos de oclusão e nenhum efeito foi } \\
\text { observado }\end{array}$ \\
\hline $\begin{array}{l}\text { Toxicidade/patogenicidade } \\
\text { c/ mamíferos silvestres }\end{array}$ & $\begin{array}{l}\text { Alimentação de ratos, } \\
\text { toupeiras e gambás }\end{array}$ & $\begin{array}{l}\text { Os animais se alimentaram de larvas } \\
\text { infectadas com } 4 \cdot 10^{8} \text { a } 6 \cdot 10^{8} \\
\text { corpos de oclusão e nenhum efeito foi } \\
\text { observado }\end{array}$ \\
\hline
\end{tabular}

Isso valoriza ainda mais a ecotoxicologia e suas ferramentas, gerando novas perspectivas para essa área de estudo no país, pois além dos novos bioprodutos a serem testados, será necessária maior interação com profíssionais das áreas de ciências agronômicas e entomologia, já que muitas vezes esses profissionais pesquisam a eficiência inseticida dos microrganismos, mas esquecem da almejada especificidade de ação, tão necessária para o uso sustentável de um produto final.

\section{REFERÊNCIAS BIBLIOGRÁFICAS}

ADDISON, J. A., 1993, Persistence and nontarget effects of Bacillus thuringiensis in soil: a review. Can. J. Forest Res., 23: 2329-2342.

ANVISA (AGÊNCIA NACIONAL DE VIGILÂNCIA SANITÁRIA), 2002, Resolução - RDC n⿳⺈ 194, de 8 de julho de 2002. Regulamentação de produtos microbiológicos. Diário Oficial da União, 11 de julho de 2002, pp. 228-229.

ANVISA (AGÊNCIA NACIONAL DE VIGILÂNCIA SANITÁRIA), 2006, Sistema de informação sobre agrotóxicos - SIA. Disponível em: http://www.anvisa.gov.br/toxicologia/sia.htm. Acessado em: 30 out. 2006.

BOISVERT, M. \& BOISVERT, J., 2000, Effects of Bacillus thuringiensis var. israelensis on target and nontarget organisms: a review of laboratory and field experiments. Biocontrol Sci. Technol., 10: 517-561.

BRASIL, 1976, Lei n⿳ำ 6.360, de 23 de setembro de 1976. Dispõe sobre a vigilância sanitária. Diário Oficial da União, 24 set., p. 12647.
BRASIL, 1989, Lei $\mathrm{n}^{\mathrm{o}}$ 7.802, de 11 de julho de 1989. Dispõe sobre agrotóxicos, seus componentes e afins. Diário Oficial da União, 12 jul., pp. 11459-11460.

BRASIL, 2002, Decreto $\mathrm{n}^{\mathrm{o}} 4.074$, de 4 de janeiro de 2002. Regulamenta a Lei n⿳⺈⿴囗十一 7.802. Diário Oficial da União, 8 jan., pp. 1-12.

BRASIL, 2006, Instrução Normativa Conjunta $\mathrm{n}^{-0}$ 03, de 10 de março de 2006. Estabelece procedimentos para obtenção de registro de agentes microbiológicos de controle. Diário Oficial da União, 15 mar., pp. 2325.

CASTRO, V. L. S. S., JONSSON, C. M., MELO, I. S. \& NUNES, F. V., 2001, Avaliação de risco ecotoxicológico de Trichoderma stromaticum usado como biopesticida. Ecotoxicol. Environ. Rest., 4: 18-24.

FOURNIE, J. W., FOSS, S. S. \& COUCH, J. A., 1988, A multispecies system for evaluation of infectivity and pathogenicity of microbial pest control agents in nontarget aquatic species. Dis. Aquat. Org., 5: 63-70.

GENTHNER, F. J., CHANCY, C. A., COUCH, J. A., FOSS, S. S., MIDDAUGH, D. P., GEORGE, S. E., WARREN, M. A. \& BANTLE, J. A., 1998, Toxicity and pathogenicity testing of the insect pest control fungus Metarhizium anisopliae. Arch. Environ. Contam. Toxicol., 35: 317-324.

GENTHNER, F. J., CRIPE, G. M. \& CROSBY, D. J., 1994, Effect of Beauveria bassiana and its toxins on Mysidopsis bahia (Mysidacea). Arch. Environ. Contam. Toxicol., 26: 90-94.

GENTHNER, F. J. \& MIDDAUGH, D. P., 1995, Nontarget testing of an insect control fungus: effects of Metarhizium anisopliae on developing embryos of the inland silverside fish Menidia beryllina. Dis. Aquat. Org., 22: 163-171. 
HOLCK, A. R. \& MEEK, C. L., 1987, Dose-mortality responses of crawfish and mosquitoes to selected pesticides. J. Am. Mosq. Control. Assoc., 3: 407-411.

IBAMA (INSTITUTO BRASILEIRO DO MEIO AMBIENTE E DOS RECURSOS NATURAIS RENOVÁVEIS), 1997, Portaria Normativa n⿳0 131, de 3 de novembro de 1997. Diário Oficial da União, 4 nov., pp. 24988-24991.

IGNOFFO, C.M., 1973, Effects of entomopathogens on vertebrates. Ann. N. Y. Acad. Sci., 217: 141-172.

INNES, D. G. L. \& BENDELL, J. F., 1989, The effects on small-mammal populations of aerial applications of Bacillus thuringiensis, fenitrothion, and Matacil ${ }^{(\mathrm{R})}$ used against jack pine budworm in Ontario. Can. J. Zool., 67: 1318-1323.

JONSSON, C. M. \& GENTHNER, F. J., 1997, Avaliação do potencial de patogenicidade e toxicidade do fungo entomopatógeno Colletotrichum gloeosporioides isolado de Orthezia em duas espécies de crustáceos. Embrapa-CNPMA, Boletim de Pesquisa, 1: 27.

LACEY, L. A., FRUTOS, R., KAYA, H. K. \& VAIL, P., 2001, Insect pathogens as biological control agents: do they have a future? Biol. Control., 21: 230-248

LACEY, L. A. \& MULLA, M. S., 1990. Safety of Bacillus thuringiensis ssp. israelensis and Bacillus sphaericus to nontarget organisms in the aquatic environment, pp. 169-188. In: M. Laird, L. Lacey \& E. Davidson (eds.), Safety of microbial insecticides. CRC Press, Boca Raton.

LACEY, L. A. \& SIEGEL, J. P., 2000, Safety and ecotoxicology of entomopathogenic bacteria, pp. 253-273. In: J. F. Charles, A. Delécluse \& Nielsen-LeRoux (eds.), Entomopathogenic bacteria: from laboratory to field application. Kluwer Academic Publishers, The Netherlands.

MATHAVAN, S. \& VELPANDI, A., 1984, Toxicity of Bacillus sphaericus strains to selected target \& non-target aquatic organisms. Indian J. Med. Res., 80: 653-657.

MAXIMIANO, A. A., FERNANDES, R. O., NUNES, F. P., ASSIS, M. P., MATOS, R. V., BARBOSA, C. G. S., OLIVEIRA-FILHO, E. C., 2005, Utilização de drogas veterinárias, agrotóxicos e afins em ambientes hídricos: demandas, regulamentação e considerações sobre riscos à saúde humana e ambiental. Cienc. Saúde Colet., 10: 483-491.

MERRITT, R. W., WALKER, E. D., WILZBACH, M. A., CUMMINS, K.W. \& MORGAN, W. T., 1989, A broad evaluation of Bti for black fly (Diptera: Simuliidae) control in a Michigan river: efficacy, carry and nontarget effects on invertebrates and fish. J. Am. Mosq. Control. Assoc., 5: 397-415.

MIDDAUGH, D. P. \& GENTHNER, F. J., 1994, Infectivity and teratogenicity of Beauveria bassiana in Menidia beryllina embryos. Arch. Environ. Contam. Toxicol., 27: 95-102.

MITTAL, P. K., ADAK, T. \& SHARMA, V. P., 1994. Comparative toxicity of certain mosquicidal compounds to larvivorous fish, Poecilia reticulata. Indian J. Malariol., 31: 43-47.

NESTRUD, L. B. \& ANDERSON, R. L., 1994, Aquatic safety of Lagenidium giganteum: effects on freshwater and fish invertebrates. J. Invertebr. Pathol., 64: 228-233.

OLIVEIRA-FILHO, E. C., 2005, Segurança de agentes microbiológicos para o controle de pragas: avaliação toxicológica, regulamentação e situação atual. Rev. Bras. Toxicol., 18: 71-75.
OLIVEIRA-FILHO, E. C. \& CASTRO, M. L. M. P., 2006, Por que regular produtos biológicos? pp. 27-30. In: E. C. Oliveira-Filho \& R. G. Monnerat (eds.), Fundamentos para a regulação de semioquímicos, inimigos naturais e agentes microbiológicos de controle de pragas. Embrapa Cerrados, Planaltina, DF.

PRACA, L. B., BATISTA, A. C., MARTINS, E. S., SIQUEIRA, C. B., DIAS, D. G. S., GOMES, A. C. M. M., FALCÃO, R. \& MONNERAT, R. G., 2004, Estirpes de Bacillus thuringiensis efetivas contra insetos das ordens Lepidoptera, Coleoptera e Diptera. Pesq. Agropec. Bras., 39: 11-16.

POLANCZYK, R. \& ALVES, S., 2003, Bacillus thuringiensis: uma breve revisão. Agrociencia, 7: 1-10.

SAIK, J. E., LACEY, L. A. \& LACEY, C. M., 1990, Safety of microbial insecticides to vertebrates - domestic animals and wildlife, pp. 115132. In: M. Laird, L. A. Lacey \& E. Davidson (eds.), Safety of Microbial Insecticides. CRC Press, Boca Raton.

SEMALULU, S. S., MAC PHERSON, J. M., SCHIEFER, H. B. \& KHACHATOURIANS, G. G., 1992, Pathogenicity of Beauveria bassiana in mice. J. Vet. Med., B39: 81-90.

SNARSKI, V. M., 1990, Interactions between Bacillus thuringiensis subsp. israelensis and fathead minnows, Pimephales promelas Rafinesque, under laboratory conditions. Appl. Environ. Microbiol., 56: 2618-2622.

TIGANO, M. S. \& MELLO, S. C. M., 2006, Fungos agentes de controle biológico, pp. 157-174. In: E. C. Oliveira-Filho \& R. G. Monnerat (eds.), Fundamentos para a regulação de semioquímicos, inimigos naturais e agentes microbiológicos de controle de pragas. Embrapa Cerrados, Planaltina, DF.

USEPA (UNITED STATES ENVIRONMENTAL PROTECTION AGENCY), 1996, Reregistration Eligibility Decision (RED), Polyhedral inclusion bodies of gypsy moth (Lymantria dispar) and douglar fir tussock moth (Orgyia pseudotsugata) nuclear polyhedrosis viruses.

EPA-738-R-96-020, September 1996. 104 p. Disponível em: http:/ /www.epa.gov/oppsrrd1/REDs/4106red.pdf. Acesso em: 5 mar. 2007.

USEPA (UNITED STATES ENVIRONMENTAL PROTECTION AGENCY), 1998. R.E.D. Facts, Bacillus thuringiensis. EPA-738-F-98001, mar., 6 p.

USEPA (UNITED STATES ENVIRONMENTAL PROTECTION AGENCY), 2007, Biopesticide active ingredients and products containing them. Disponível em: http://www.epa.gov/pesticides/ biopesticides/product_lists/bppd_products_by_AI.pdf. Acesso em: 5 mar. 2007.

VAN FRANKENHUYZEN, K. V., 1993, The challenge of Bacillus thuringiensis. pp. 1-35. In: P. F. Entwistle, J. S. Cory, M. J. Bailey, \& S. Higgs, (eds.), Bacillus thuringiensis, An Environmental Biopesticide: Theory and Practice. John Wiley \& Sons, New York.

WALTON, W. E. \& MULLA, M. S., 1991, Integrated control of Culex tarsalis larvae using Bacillus sphaericus and Gambusia affinis: effects on mosquitoes and nontarget organisms in field mesocosms. Bull. Soc. Vector Ecol., 16: 203-221.

WHO (WORLD HEALTH ORGANIZATION), 1981, Mammalian safety of microbial agents for vector control: a WHO memorandum. Bull. World Health Organ., 59: 857-863.

WHO (WORLD HEALTH ORGANIZATION), 1999, Bacillus thuringiensis. Environmental Health Criteria, 217. WHO, Geneve, 105 p. 